\title{
A RODA DE LEITURA LITERÁRIA NAS VIVÊNCIAS DE EXTENSÃO NO PROJETO MÃOS DE VIDA
}

\author{
Maria Glória DitTrich ${ }^{1}$ \\ ORCID: 0000-0003-2107-9005 \\ Cleide J Müller Pareja ${ }^{2}$ \\ ORCID: 0000-0002-5576-2980 \\ VANDerléa Ana Meller ${ }^{3}$ \\ ORCID: 0000-0002-5342-2659
}

\begin{abstract}
Resumo: A leitura como exercício vital-cognitivo, que atravessa culturalmente a vida do ser humano, é uma dinâmica criativa fundamental do saber e formação educativa, especialmente em uma visão transdisciplinar. O presente estudo teve como objetivo apresentar as atividades de Roda de Leitura Literária Transdisciplinar realizadas com as crianças e jovens de instituições sócio educativas pelo Projeto de Extensão "Mãos de Vida”, da UNIVALI. É um estudo de abordagem qualitativa, com base no método hermenêutico fenomenológico, realizado a partir de intervenções educativas com 30 crianças e jovens da Instituição Lar Fabiano de Cristo e Parque Dom Bosco,
\end{abstract}

1 Filósofa, Mestre em Educação e Doutora em Teologia. Professora, Pesquisadora e Coordenadora do Mestrado Profissional em Gestão de Políticas Públicas e Professora da Universidade do Vale do Itajaí (UNIVALI/SC), Coordenadora do Projeto de Extensão "Mãos de Vida". E-mail: (gloria. dittrich@univali.br, gloria.dittrich@univali.br).

2 Doutoranda em Educação. Professora da Universidade do Vale do Itajaí. Integrante do Projeto de Extensão Mãos de Vida. E-mail: (cleidepareja@hotmail.com).

3 Doutora em Educação. Professora da Universidade do Vale do Itajaí. Integrante do Projeto de Extensão Mãos de Vida da UNIVALI. E-mail: (vanderlea@univali.br). 
Itajaí, SC. Os resultados evidenciaram que a organização da "Roda de Leitura Transdisciplinar" proporcionou às crianças e jovens o acesso aos textos literários e valorização da leitura por meio da contação de histórias; mobilizou diferentes linguagens, em especial a oralidade e expressão corporal; ampliou o mundo de fantasia, garantido pelos próprios mecanismos psicológicos envolvidos no imaginário expresso; fortaleceu o equilíbrio psicoemocional e o humanescer; colaborou com as habilidades interpretativas e reflexivas em torno dos temas e entendimento dos valores humanos e sociais; facilitou a interação entre os pares nos jogos expressivos e linguísticos provocadores diversos significados e sentidos para o viver e conhecer.

Palavras-chave: Leitura literária. Vivência transdisciplinar. Extensão Universitária.

\title{
THE LITERARY READING WHEEL IN EXTENSION EXPERIENCE IN THE HANDS OF LIFE PROJECT
}

\begin{abstract}
Reading as a vital-cognitive exercise, which crosses the life of a human being culturally, is a fundamental creative dynamic of knowledge and educational formation, especially in a transdisciplinary view. The present study aimed to present the activities of the Transdisciplinary Literary Reading Wheel carried out with children and young people from socio-educational institutions by the UNIVALI Extension Project "Hands of Life". It is a qualitative approach study, based on the phenomenological hermeneutic method, conducted from educational interventions with 30 children and young people from the Lar Fabiano de Cristo Institution and Dom Bosco Park, Itajaí, SC. The results showed that the organization of the "Transdisciplinary Reading Wheel" provided children and young people with access to literary texts and valorization of reading through storytelling; mobilized different languages, especially orality and body expression; expanded the fantasy world, guaranteed by the psychological mechanisms involved in the imaginary itself; strengthened psycho-emotional balance and humanescence; collaborated with interpretative and reflective skills around themes and understanding of human and social values; It facilitated the interaction between the pairs in the expressive and linguistic games that provoked various meanings and meanings for living and knowing.
\end{abstract}

Keywords: Literary Reading. Transdisciplinary experience. Universuty Extension.

\section{LA RUEDA DE LECTURA LITERARIA EN EXTENSIÓN EXPERIMENTA EN EL PROYECTO MANOS DE LA VIDA}

Resumen: La lectura como ejercicio cognitivo vital, que atraviesa la vida cultural de un ser humano, es una dinámica creativa fundamental de conocimiento y formación educativa, especialmente en una visión transdisciplinaria. El presente estudio tuvo como objetivo presentar las actividades de la Rueda de lectura literaria transdisciplinaria llevada a cabo con niños y jóvenes de instituciones socioeducativas por el Proyecto de extensión de UNIVALI "Manos de vida". Es un estudio de enfoque cualitativo, basado en el método hermenéutico fenomenológico, realizado a partir de intervenciones educativas con 30 niños y jóvenes de la Institución Lar Fabiano de Cristo y el Parque Dom Bosco, Itajaí, SC. Los resultados mostraron 
que la organización de la "Rueda de lectura transdisciplinaria" proporcionó a niños y jóvenes acceso a textos literarios y valorización de la lectura a través de la narración de cuentos; movilizó diferentes idiomas, especialmente oralidad y expresión corporal; expandió el mundo de fantasía, garantizado por los mecanismos psicológicos involucrados en el imaginario mismo; fortalecimiento del equilibrio psicoemocional y la humanidad; colaboró con habilidades interpretativas y reflexivas sobre temas y comprensión de los valores humanos y sociales; Facilitó la interacción entre las parejas en los juegos expresivos y lingüísticos que provocaron diversos significados y significados para vivir y conocer.

Palabras claves: Lectura literaria. Experiencia transdisciplinaria. Extensión Universitaria.

Submetido em: 27/08/2019.

Aceito em: 27/09/2019.

\section{INTRODUÇÃO}

A arte é a manifestação pura dos processos criativos do ser humano, como expressão legítima de sua capacidade de pensar-sentir-fazer e conviver nos processos educativos emancipatórios. Dentro dessa visão os integrantes do Projeto de Extensão "Mãos de Vida: uma escola criativa para humanescer na cidadania" optaram por realizar uma proposta de prática educativa envolvendo a arte literária, denominada "Roda da leitura literária transdisciplinar". As intervenções práticas foram realizadas com crianças e jovens do Instituto Lar da Juventude de Assistência e Educação Parque Dom Bosco e no Instituto Lar Fabiano de Cristo, localizados em Itajaí.

A leitura do literário oportuniza abertura de consciência para o desenvolvimento de um imaginário criativo que se tece nos processos vitais-cognitivos do ser humano desde suas intuições e percepções. Nesse processo, a dinâmica criativa impulsionada por uma energia de amorosidade, para com o encanto do belo no imaginário, atravessa as dimensões biofísica, psíquica, espiritual e sociocultural no do ser humano, conectando inter e transdisciplinar saberes e metodologias capazes de fundamentar uma linguagem sensitiva e racional, e que vai no percurso aflorando discursivamente. Tal processo desperta a percepção no sentido de viabilizar compreensões referentes às relações mais diversas construídas no caminho de sua existência familiar e comunitária. É por meio da leitura textual em diferentes gêneros que se torna possível organizar o conhecimento envolvido na sensibilização e recriar processos imagéticos que se organizam racionalmente em argumentos, ampliando potencialidades e pensamentos como 
leitor refletindo e formando os próprios conceitos e consequentes ligações estabelecidas com o autor e com o conhecimento promovido.

Para Zappone (2009) o texto é um fenômeno quando apreendemos sua essência, isso é possível por meio da experiência do sujeito, que é o leitor. $\mathrm{Na}$ experiência da leitura a obra literária é dado à consciência do leitor, a realidade do literário se torna integrada à consciência de quem percebe, na subjetividade. Ler é, inclusive, criar o texto e nesse sentido as raízes da "Estética da Recepção", como uma fenomenologia para o leitor que considera o fenômeno afetado pela percepção.

Incontáveis benefícios surgiram na vida cotidiana desde descobertas da leitura promovidas pela criatividade humana nas diversas produções que registram quadros fenomenológicos das vivências e descobertas, criando e recriando, permanentemente, explicações sobre o ser humano e a cultura.

Candido (1995, p. 186) por sua vez, considera que "a literatura corresponde a uma necessidade universal que deve ser satisfeita sob pena de mutilar a personalidade, porque pelo fato de dar forma aos sentimentos e a visão do mundo ela nos organiza, liberta-nos do caos e, portanto, nos humaniza". Para o autor "negar a fruição da literatura é mutilar a nossa humanidade” (CANDIDO, 1995, p. 186).

Ao valorizar a leitura entendemos sua função social e cultural e, na extensão universitária, como uma política educacional institucional na Universidade do Vale do Itajaí, buscamos oportunizar vivências educativas por meio da leitura literária, com os propósitos de uma escola criativa com formas de sentir, pensar e agir inter e transdisciplinares. Essa formação visa, cotidianamente, aprendizagens que oportunizem vivências de significados e sentido de vida das pessoas envolvidas. Como afirma Battalloso (2011) a escola criativa é aquela que concebe o desenvolvimento da criatividade como algo que vai além dos mecanismos de processamento de informação e de habilidades cognitivas.

Dentro dessa visão, o projeto de Extensão "Mãos de Vida "Mãos de Vida: uma escola criativa para humanescer na cidadania", da Universidade do Vale do Itajaí, em Itajaí - SC atua com foco na visão da Rede Internacional de Escolas Criativas (RIEC). Seu objetivo implica promover práticas educativas com base em instituições socioeducativas para a promoção da educação e da saúde comunitária de crianças e jovens em condição de vulnerabilidade social. A estrutura metodológica foi desenvolvida dentro de uma visão transdisciplinar e ecoformativa tendo em vista o fortalecimento da pessoa na sua relação com o outro, a cultura e a natureza. 
Com efeito, esta abordagem considera que as relações de aprendizagens se dão em uma rede complexa de linguagens de conversações simbólicas carregadas de saberes e formas de ser e conviver, que levam a um fazer e aprender interligado com a cultura. Sustentando esta ideia, Maturana (2004, p. 7) destaca que os processos do aprender a aprender se constituem como "uma rede fechada de conversações". Ou seja, a emergência de linguagens carregadas de significados e significantes que apontam coordenações consensuais de condutas conservadas (ou coordenações de ações e emoções) de modo transgeracional no devir humano.

No Projeto de extensão "Mãos de Vida", o fenômeno acima citado desvelou-se na "Roda de Leitura Transdisciplinar", pois desponta de modo espontâneo na prática da leitura literária, em um processo de formação permanente que gera um diálogo envolvido nas especificidades de um grupo, de um contexto social que é aberto à diversidade de saberes ao emocionar-se com a vida, nas dinâmicas que atravessam as corporeidades e se integram às histórias das pessoas envolvidas, despertando nelas os mais subjetivos significados. Nas diversas atividades desenvolvidas, o projeto vem gerando impactos sociais, acadêmicos e profissionais, envolvendo produções tecnológicas na educação e no cuidado em saúde, as quais são realizadas por uma equipe transdisciplinar de professores das áreas de Psicologia, Educação Física, Nutrição, Medicina, Letras, Arteterapia, Filosofia e Mestrado de Políticas Públicas.

A visão transdisciplinar propõe uma "reforma do pensamento", proposta por Morin (2003), reformar o pensamento para reformar o ensino, e reformar o ensino para reformar o pensamento. Entre as ações possíveis para esses propósitos, a leitura tem função primordial, pois a "Literatura, poesia e cinema devem ser considerados além de objetos de análises, escolas de vida em seus múltiplos sentidos". (MORIN, 2003, p. 48). Esses são registros culturais que poderão ser visitados e que muito contribuirão com as dinâmicas do pensamento complexo que se auto-organiza constantemente na organização do conhecimento.

\section{O PROCESSO METODOLÓGICO}

A Foi realizado um estudo de abordagem qualitativa, amparado na hermenêutica fenomenológica (MERLEAU-PONTY, 1999), para a compreensão dos fenômenos e os possíveis resultados que foram expressos descritivamente. Nessa mesma direção Dittrich; Leopardi (2015, p. 99) afirmam que 
[...] a hermenêutica fenomenológica, diz respeito a uma postura, uma maneira de entender e expressar a percepção sobre os acontecimentos que ocorreram entre os sujeitos envolvidos nas vivências, compartilhadamente, no amor e na solidariedade entre os saberes e as ações.

A pesquisa fenomenológica busca perceber um conjunto de fenômenos e como se manifestam no tempo e espaço, a fim de chegar à essência das coisas e como elas são percebidas no mundo desde a consciência do pesquisador.

Os procedimentos na hermenêutica fenomenológica consideraram que a relação entre o pesquisador e o seu objeto se constitui em síntese perceptiva e compreensiva.

As intervenções da "Roda de leitura literária transdisciplinar" foram realizadas com crianças e jovens do Lar Fabiano de Cristo e Parque Dom Bosco na cidade de Itajaí - SC, atingindo semanalmente 40 participantes e organizadas pelos professores e bolsistas do projeto de extensão supracitado, tendo também colaboração do Grupo Contarte da UNIVALI composto por alunos de Letras e História.

\section{A RODA DE LEITURA LITERÁRIA TRANSDISCIPLINAR}

[...] cada palavra de um texto difícil desperta em nós pensamentos que anteriormente nos pertenciam, mas por vezes essas significações se unem em um pensamento novo que as remaneja a todas, somos transportados para o centro do livro, encontramos a sua fonte (MERLEAU-PONTY, 1999, p. 243).

A "Roda de leitura literária transdisciplinar" foi oportunidade de encontrar a fonte da vida no despertar do encantamento do aprender desde uma vivência de educação estética, que prioriza a experiência fenomênica da articulação das sensações, emoções, intuições e percepções sobre o afloramento do imaginário simbólico e metafórico na contação de estória. Tal processo prima, ecoformativamente, por vivências capazes de oportunizar o humanescer na educação de crianças em vulnerabilidade social. Para Dittrich; Uriarte (2017, p. 14) o fenômeno do humanescer na educação implica "deixar florescer o humano no humano que existe em cada pessoa e que se mostra na capacidade de respeito e amorosidade no saber pensar e agir com criatividade e criticidade, tendo em vista o bem".

A leitura é exercício humanizante com os livros lidos, quando se reconhece em cada atitude e cada reflexão do personagem reflexos do ser humano em si, pois ele se identifica com as histórias, nas expressões e cenários, nas lembranças do mundo vivido e nos desejos de viver experiências. O papel fundamental da literatura.

confirma no homem aqueles traços que reputamos essenciais, como o exercício da reflexão, a aquisição do saber, a boa disposição para com o próximo, o afinamento das 
emoções, a capacidade de penetrar nos problemas da vida, o senso da beleza, a percepção da complexidade do mundo e dos seres, o cultivo do humor (CANDIDO, 1995, p. 180).

A organização das práticas foi planejada a fim de promover o envolvimento simbólico e real, possível e riquíssimo na leitura literária. No desenvolvimento da Roda de Leitura Literária Transdisciplinar organizamos as seguintes etapas:

1. Encontro do grupo para a escolha temática: Seleção dos literários ocorreu conforme temas relevantes para o auxílio às necessidades conceituais emergentes para a prática efetivada no projeto. Diante das obras escolhidas os graduandos bolsistas e professores da graduação organizaram as leituras com diferentes estratégias e recursos.

2. Organização para atuação: Primeiramente, ocorreu o preparo do ambiente energeticamente, para receber as pessoas num propósito acolhedor de amorosidade à vida e ao encontro dos envolvidos. Os recursos para acomodação da sala foram dispostos em círculo para a efetivação simbólica em diferentes linguagens e propósitos temáticos, configurando uma imagem para a dinâmica da "Roda de Leitura Transdisciplinar” como símbolo circular integrador. Também, músicas-ambiente foram selecionadas de acordo com a proposta do dia. Atividades de preparação das pessoas são realizadas com atividades corporais de sensibilização para abertura de consciência e desenvolvimento do foco para a leitura. A concentração foi aguçada para a reflexão em relação à existência.

3. A circularidade da "Roda de Leitura Transdisciplinar": Foi organizada com diferentes práticas envolvendo o contato com os literários, com diferentes estratégias para a leitura dos textos em uma ação educativa transdisciplinar para a formação de leitores. Ocorreram diversas práticas com foco no ser criativo e problematizador, envolvendo todos de maneira integrada. A leitura buscou mobilizar o acesso sensível ao conhecimento e à reflexão interativa. Foram envolvidos temas ligados ao ser humano e o cuidado à vida e à saúde, educação, à sociedade, aos valores humanos, ecoformação, à arte, ludicidade, entre outros, visando a autorreflexão e a significação do sentido de viver. Ocorreram diálogos na interlocução com perguntas, reflexões e respostas para se chegar às novas compreensões sobre os referidos temas presentes nas obras literárias e poesias.

4. Fechamento da Roda: Ocorreu a síntese descritiva expressiva, pessoal e após coletiva. Cada participante teve a oportunidade de expor suas compreensões finais ao grupo sobre o tema em estudo, bem como este processo auxiliou na ampliação de domínios categóricos-conceituais no campo da ciência, arte, lieteratura e filosofia do ponto de vista teórico e meotodológico. Tais expressões possibilitaram ressignificações em torno dos significados e sentidos de ser, viver e fazer humano. 
No Lar Fabiano de Cristo as crianças fizeram um passeio com várias histórias pelo mundo das relações humanas e com a natureza. Em "Druska", de Neitzel (2018), a conexão com a alegria e a brincadeira que o cãozinho sempre faz ao encontrar seu amigo, seu parceiro demonstrando sempre a felicidade de estar com. O reconhecimento de que as diferenças que muitas vezes nos incomodam podem ser a nossa evolução em "Pata Ti e Pata Tá" de Fabiana Dollor (1999). Rejeitadas pelo seu jeito atrapalhado de cantar as patinhas acabam salvando todos os companheiros do galinheiro afastando os ladrões. O que parecia um defeito transformou-se em qualidade. O encanto com o perigo e a figura ontológica do lobo que tanto afetam as crianças esteve presente em duas versões "Os 33 porquinhos e os Jacarezinhos atrapalhados"(TORERO;PIMENTA,2016), a história adaptada pela professora responsável pelo ContArte. O maravilhamento com as possibilidades de transformação do feio para o belo foi vivenciado na obra "A primavera da Lagarta” de Rocha (2011). O tema sobre relações afetivas e seus efeitos sociais foram pensados a partir das histórias "Eles que não se amavam" de Sisto (2005) e "Romeu e Julieta", de Rocha (2009).

Após cada intervenção realizamos uma "roda de conversa" para que as crianças e jovens refletissem, questionassem, deixassem fluir as emoções ocorridas na atividade. Foram encontros literários que despertaram sensivelmente as crianças e jovens para a convivência na paz, diversidade, respeito, alteridade e entendimento dos valores necessários para a vida em harmonia e seu fortalecimento nas dinâmicas internas do ser humano e suas relações com o meio em toda complexidade. Foi envolvida uma mistura entre mundo imaginário e real, pois "A cada instante também eu fantasio acerca de coisas, imagino objetos ou pessoas cuja presença aqui não é incompatível com o contexto, e todavia eles não se misturam ao mundo, eles estão adiante do mundo, no teatro do imaginário" (MERLEAU;PONTY, 1999, p. 6). Não foram meras representações, mas percepções ampliadas envolvidas nas experiências vividas que resultaram em compreensões fundamentais para a emancipação humana.

No Parque Dom Bosco iniciamos com a obra "Margarida" de Neves (2010), história que mostra a realização de sonhos inusitados como uma vaca estabelecer profunda afetividade por um peixe-boi, envolvendo a admiração e interação entre diferentes seres. O ciúme e a inveja, sentimentos fortes nos seres humanos, foram pensados a partir de "Branca de Neve" dos Irmãos Grimm (2019). Sobre o desejo de ser amado pelos pais contamos a histórias "Um dedinho de amor" de Lucinda (2002). Os problemas de relacionamento entre os casais são vivenciados na obra "A moça tecelâ" de Colasanti (2009). Uma lenda judaica demonstra o poder da circularidade da vida no conto "De pouco de faz muito" de Gilman (2004) a possibilidade 
de entender de como todas as pessoas podem ser fadas, lemos na história intertextual "Fadas que não estão nos contos de fadas" de Canton (2010). Várias versões de Natal, para diferentes pessoas e religiões se fizeram presentes nas obras "O espírito do Natal" de Letria (2015) e "Mais ou menos Natal" de Sheldon e Grindley (2014).

A quebra do paradigma do dualismo bem e mal foram apresentados na obra "A vassoura da Bruxa" de Rios (1993). A sintonia entre os diferentes e a morte são apresentados no enredo de "Bicos Quebrados" de Lachenmeyer (2004). A circularidade da vida esteve presente na oficina "Infinita Fiandeira", de Mia Couto (2016) e também nos poemas sobre mandalas do poeta Bashô.

O texto poético foi apresentado com a performance "As desrazões do homem" com poemas de autores consagrados com adaptação realizada pela coordenadora do ContArte, Cleide Pareja. Com o Sarau "Poesia na Varanda" de Junqueira (2011) os alunos foram convidados a fazer uma apresentação junto com os integrantes do projeto "Mãos de vida". Ainda, na Oficina "Você é o Contador" as crianças e jovens foram preparados em equipes para contarem as histórias escolhidas por eles nos roteiros do ContArte e foi um momento de muita expressividade e alegria para todos os participantes.

Na vivência realizada a partir da leitura da obra "Para que serve o livro?" de Legay (2012) foram abertas as discussões avaliativas sobre a Roda de Leitura. Foi possível evidenciar que as atividades com a leitura dos textos literários, e também contato com os poemas e estímulos às atividades corporais em diferentes linguagens possibilitaram a criatividade expressiva dos desejos, sonhos, condições sociais e humanas, despertando culturalmente para a leitura, para o outro, para si e para o mundo.

\section{EXPRESSÕES NA RODA DE LEITURA LITERÁRIA TRANSDISCIPLINAR}

"Vocês estão aqui para nos dar apoio,

para abrir nossos corações"

(Lia).

O que de nós está no outro? Eis a questão que se põe ao ofertar o contato e as trocas, envolvidas nas histórias que não sabemos ao certo onde iniciaram e que não tem fim, mas que possibilitam sonhar e realizar, também a coragem para enfrentar os desafios e resolução de conflitos. Reconhecemos que, ao soprar a palavra se sopra a energia como movimento do espírito criador da vida atuando no humano. O sopro da palavra é um fenômeno que nasce das profundezas abissais 
do ser humano, na dinamys dos seus processos vitais-cognitivos, com força de vida que cada criança e jovem pode sentir e reconhecer na interrelação com outro, pois vida-conhecimento, num amplo sentido, não se separam. (DITTRICH, 2010; 2016). É possível sentir esse afetamento na fala da aluna Rose, "Hoje cheguei triste e ao final do encontro fiquei bem".

Observamos a validade das relações construtivas estabelecidas pelas histórias e enredos compartilhados, a transformação para o humanescer dos jovens e crianças, pois iniciaram os encontros tensas e agitadas e, a cada leitura, mobilizando diversas atividades corporais expressivas, foram encontrando o centro pessoal de paz e harmonia, atingindo a coletividade. Nesse envolvimento, para o aluno Marcos, "Adoro teatro e fazer as contações, me dá alegria que quase eu nunca tenho".

Foram práticas que ampliaram sentimentos e relações de diálogo, muito necessárias à educação atual. Na visão de Bauman (2008), o século passado sofreu uma passagem da sociedade de produção tecnológica para a sociedade de consumo. Com efeito, nessa troca de foco cultural na construção da existência, o ser humano vive o processo de fragmentação do ler sobre as relações do viver humano, bem como do conhecimento que implica a forma de pensar, conhecer e agir.

Na retomada sensibilizadora do humano, por meio da leitura dos literários, os jovens e crianças passaram a expressar mais tranquilidade no olhar e nos gestos, compartilhando com a proposta de contação e envolvendo-se atenciosamente com os livros, até relaxando no tapete e almofadas dispostas para o acolhimento. Todos acomodavam-se em paz em torno do espaço de leitura aguardando avidamente o mundo que sairia de dentro de cada uma daquelas histórias. $\mathrm{O}$ encantamento era observado na tranquilidade e energia do corpo em diferentes posições que demonstrava envolvimento atencioso, prazeroso e afetivo. Era possível sentir o desejo de um momento infinito, pois sempre queriam mais e expressam satisfação com as atividades, para Tiago "Como é bom ouvir histórias, eu imagino que estou junto vivendo ela, dá uma emoção"; para Lucas "Como foi bom apresentar-se contando história e recitando versos".

Foram oportunidades que

Sente-se, assim, o ato de ler como algo posto na voz ativa e na voz passiva simultaneamente. Na leitura, voz ativa e voz passiva são inseparáveis: se entrelaçam. O leitor está sempre entre o linguístico e o extralinguístico. Entre o dito e o não-dito. As circunstâncias são os pressupostos implícitos da linguagem [...] (BERTICELL; SCHIAVIN, 2013, p. 576).

Nas oportunidades para dizer, as relações e desejos de contato foram se ampliando e as crianças e jovens passaram a nos abraçar e beijar, com desejo 
espontâneo, amorosidade e sem preconceito. Foi possível sentir que envolviam-se em nossos braços cruzando uma intensa energia e que também possibilitava motivação e desejo para dar continuidade ao projeto. As crianças e jovens expressaram que "Melhorou a nossa interação no grupo" (Pedro); "Melhoramos na leitura" (Maria); "Percebemos que a informática dá informação, mas não faz a gente pensar tanto como fazem os livros" (Ana); "Melhorou o entendimento das palavras nas aulas de português” (Alice); “Ler é como estudar, compartilhar" (André).

Identificamos que os bolsistas do projeto também foram afetados pelos contatos com os literários e relações estabelecidas. Bruna revelou que após as intervenções definiu a sua futura especialização, e que será em Pediatria, pois sentiu-se realizada ao interagir com as crianças. E ainda expressou: "Por causa das atividades de leitura me tornei mais divertida, converso mais, e estou mais presente nas coisas que faço."

A proposta, a partir da valorização da leitura e da contação de história e poemas, oportunizou mudança de paradigma de pensamento, saindo de uma visão racionalista e biomédica para a saúde e educação, convergindo na direção de um pensamento complexo, evidenciado por Morin (2011), e também transdisciplinar. Foram avanços fundamentais em torno das posturas críticas e reflexivas em que as relações de prazer para e com a leitura foram aguçadas. As vivências estabelecidas possibilitaram fundamentação e ampliação do entendimento dos sentimentos e conhecimentos envolvidos.

Nesse envolvimento Carla afirmou, reflexivamente, a descoberta de alguns conceitos e abrangência quando disse: "Eu preciso ler muito, pois este tema é profundo, tem muitas coisas para descobrir ainda”. O despertar para diferentes conhecimentos tornou-se possível por meio dos literários que são carregados de saberes “[...] entende-se que a formação de leitores exige o contato constante com textos que os deixem intrigados e os lancem à busca de significados, textos que os desafiem a perceber diferentes verdades, textos que deem licença ao sentir [...]" (NEITZEL; BRIDON; WEISS, 2016, p. 307-308).

Entre sentimentos e saberes a leitura, como bem cultural, promoveu diferentes forças que moveram para o contato humanizado e afetivo carregado de desejos de saber e de amorosidade.

\section{O ENVOLVIMENTO COM A LEITURA NO PROJETO DE EXTENSÃO}

Desde 2011 que ações de leitura e envolvimento criativo com os textos literários são desenvolvidos nas formações permanentes dos acadêmicos, professores, 
crianças e jovens participantes do projeto de extensão "Mãos de vida". Foram envolvidas as leituras textuais e diálogos em torno das histórias, e reflexões que atravessaram diferentes saberes, idiossincrasias e abordagens que impactaram positivamente o acesso e manutenção da leitura. Ler tornou-se uma atitude e estratégia para os encontros e encantamentos com as obras, no contato com a arte e a cultura, e

Sente-se, assim, o ato de ler como algo posto na voz ativa e na voz passiva simultaneamente. Na leitura, voz ativa e voz passiva são inseparáveis: se entrelaçam. O leitor está sempre entre o linguístico e o extralinguístico. Entre o dito e o não-dito. As circunstâncias são os pressupostos implícitos da linguagem [...] (BERTICELL; SCHIAVIN, 2013, p. 576).

A leitura foi uma prática fundamental para o contato ampliado com vocabulários, conceitos e interpretações na construção do hábito de ler e das aprendizagens. $\mathrm{O}$ acesso ao conhecimento foi possível por meio das leituras e interpretação necessárias ao entendimento. A escrita também foi vinculada à leitura, no registro dos pensamentos e imagens que favoreceram a expressão da cultura e práticas sociais com possibilidades de diálogo ampliados, expressões em diferentes linguagens.

O envolvimento textual contribuiu para o acesso ao conhecimento no universo da literatura, da arte e da ciência, em determinadas áreas e propósitos. A princípio, no grupo de profissionais do projeto de extensão "Mãos de Vida", identificamos que as leituras demarcavam, demasiadamente, territórios técnicos de saberes muito específicos com a área de atuação de cada um, tornando o vocabulário limitado, e principalmente com expressões amplamente objetivadas. Sentimos falta de uma linguagem mais sensibilizada e poética nas atuações e produções, pois essa a realidade dificultava as produções textuais na perspectiva transdisciplinar. Para Moraes (2015) a transdisciplinaridade é uma postura e prática na construção do saber e do conviver que se autoeco-organiza em uma tessitura de saberes que se atravessam entre si e além de si para o surgimento de novos saberes.

Para Zappone (2009) o texto é um fenômeno quando apreendemos sua essência, isso é possível por meio da experiência do sujeito, que é o leitor. Na experiência da leitura a obra literária apresenta-se à consciência do leitor, a realidade do literário se torna integrada à consciência de quem percebe, na subjetividade. Ler é, inclusive, criar o texto e nesse sentido as raízes da Estética da Recepção, como uma fenomenologia para o leitor, considera o fenômeno afetado pela percepção.

Em torno das necessidades de sensibilização e ampliação dos saberes e conteúdos para tratar de temas pertinentes à missão do projeto, especialmente na abordagem ecoformativa e transdisciplinar, as reuniões de formação na "Roda de Leitura" foram planejadas e organizadas com alguns temas transdisciplinares que 
envolveram a filosofia, a sociologia, as artes, a saúde e a educação. Foram escolhas apropriadas, pois o projeto atingia profissionais da área da saúde e das humanidades que atuavam em contextos socioeducativos e com pessoas que apresentavam muitas necessidades de diálogo e interligação de saberes.

Buscamos leituras em torno da "estética da recepção" (ZAPPONE, 2009, p. 162) e o envolvimento sensível e imprevisível do leitor com a obra, pois “[...] os textos são passíveis de diferentes recepções porque lidos por públicos diferentes no tempo e no espaço, o status desses textos também se modificam [...]" Nesse contexto, estabelecemos envolvimentos com as obras que permitiram as entradas criativas dos leitores e provocaram perspectivas sobre as relações do ser humano-sociedade-natureza e transcendência. A "Roda de leitura transdisciplinar" surge como possibilidade de abertura e ampliação do pensar criativo, poético, simbólico e crítico, envolvido na metalinguagem, com diversidade no vocabulário, tendo em vista a ampliação da compreensão entre o conhecimento do senso comum, das humanidades e das ciências.

Foi possível reconhecer que

[...] cada palavra de um texto difícil desperta em nós pensamentos que anteriormente nos pertenciam, mas por vezes essas significações se unem em um pensamento novo que as remaneja a todas, somos transportados para o centro do livro, encontramos a sua fonte. (MERLEAU-PONTY, 1999, p. 243).

Renovar o pensamento reflexivo, buscando remanejar a imaginação e as habilidades de criação, em cada literário reconhecido, foram avanços que consolidaram a importância da leitura nas ações educativas.

\section{CONSIDERAÇÕES FINAIS A PARTIR DAS VIVÊNCIAS NO GRUPO DE EXTENSÃO}

O desejo de ler foi aguçado com a escolha dos temas desenvolvidos, pois contribuíram para compreender as relações conceituais que emergiam. A coletividade na leitura e escuta dos textos literários e poesias nos encontros foram reflexivos e sensibilizadores para o ato de ler. A cada trecho que dialogávamos foi desejado a continuidade das leituras. Realizamos um circuito de leitura que possibilitou a integração do grupo, o fortalecimento da expressão, do pensamento, da sensibilidade, o desenvolvimento da escrita e a fluência na comunicação.

A constituição da "Roda de Leitura Transdisciplinar", possibilitou o acesso e envolvimento com as leituras literárias ofertadas em contações de histórias que 
promoveram, amplamente, aprendizagens e transformações qualitativas das crianças e jovens em suas caraterísticas biofísicas, psíquicas, espirituais, socioculturais e ecológicas.

O leitor, ao se relacionar com as diferentes obras literárias, aguçou o prazer pela leitura demonstrando apreciação da obra. Nesse contexto, foi possível perceber que os jovens e crianças despertaram para o gosto de ler e desejaram, em muitos momentos, levar os livros para casa, demonstrando a vontade de dar continuidade ao exercício fruitivo da leitura.

A sensibilização, perante os temas e conceitos dos textos, foi amplamente evidenciada no desejo de ler e ouvir. Foram realizadas muitas práticas criativas com expressões escritas e posterior construção de painéis interativos. As imagens artísticas ilustrativas contidas nos livros foram provocadoras do imaginário e aguçaram a expressão individual e coletiva, despertando sensações, valores, descobertas...

Perante as inúmeras expressões dos participantes ficou evidente o desejo de ler mais intensamente, ocorreu o reconhecimento da necessidade de ler e ouvir a fim de ampliar o conhecimento. Foi perceptivo que as vivências de leitura tocaram níveis profundos de consciência de si e do mundo, propiciando o fortalecimento do olhar transdisciplinar nos diferentes saberes e recursos, com inúmeros reconhecimentos temáticos e linguagens expressivas, individuais e coletivas. As práticas desenvolvidas e as teorias estudadas resultaram em momentos educativos dos acadêmicos da UNIVALI, com bases teóricas que integram as "Rodas de Leitura Transdisciplinar", com a riqueza cultural e artística das contações de histórias.

No campo da educação, dentro de um mundo globalizado, em redes de informações e de conhecimentos, com diferentes saberes e fenômenos culturais, o ser humano vem mostrando sua necessidade de ampliar seu potencial de leitura, principalmente no reencontro com os literários. Tal necessidade implicou comunicação e oportunizasse de atuação sobre a realidade, com criação de soluções para o contato cultural com a leitura do literário.

$\mathrm{Na}$ leitura, com o exercício estético e educativo que atravessa culturalmente a vida do ser humano ocorre uma dinâmica criativa fundamental do saber na formação humana. Na atuação universitária da UNIVALI os propósitos da leitura perpassam ações envolvidas no ensino-pesquisa-extensão, especialmente dentro de uma visão inter e transdisciplinar. A proposta oportunizou abertura de consciência para cruzar saberes e metodologias capazes de fundamentar uma linguagem discursiva, que viabiliza a compreensão das relações ser humano-sociedade-natureza. Foi possível a leitura textual em diferentes gêneros, ampliando a organização do conhecimento envolvido na sensibilização e recriação de 
argumentos. Também mobilizou potencialidades e opiniões dos leitores, refletindo e formando nossos próprios conceitos e consequentes ligações estabelecidas com o autor e em torno do conhecimento promovido.

Incontáveis benefícios surgiram na vida cotidiana, desde as descobertas da leitura e expressão da criatividade humana nas diversas produções, as quais registram quadros fenomenológicos das vivências e percepções, criando e recriando permanentemente explicações sobre o ser humano e a cultura.

Vivemos diante de uma rede de relações comerciais e de ensino veloz na criação de produtos, serviços e culturas. Esse fenômeno atravessa a vida intramuros da educação e cada vez mais amplia estratégias de incentivo ao consumo rápido, de informações e produtos, que vão modelando a forma de pensar e de agir do humano. Isso promoveu reflexões sobre o sentido do ato de educar por meio da leitura literária que oportunizou aprendizagens significativas para a vida e na promoção sensível- reflexiva humana.

Ficou evidente que ao consumir a informação rápida, sem precisar pensar com base em uma leitura reflexiva e que leve à problematização de questões pertinentes aos conteúdos de aprendizagem, é a tônica num quadro de vivência de consenso para o superficial, o descartável, o prático repetitivo. Exemplos são as cópias superficiais de informações e conhecimentos que as pessoas fazem da internet, sem determinados critérios de validade da pertinência e coerência do saber.

Foi possível desestabilizar resistências para a leitura literária buscando a fruição, com leitura de obras clássicas que demandam reflexão, criatividade, concentração, interpretação e recriação do pensar e do agir diante da realidade dinâmica. Muitas vezes, tem-se a impressão que a tecnologia fez grandes avanços beneficiando o mundo da vida, porém, uma grande maioria de pessoas são fascinadas por ela tornado alienando o pensar profundo e problematizador.

Nos processos de leitura literária na extensão foi possível identificar que é necessário, sempre, vencer os motivos enfraquecedores do pensar em termos de capacidade de foco, de atenção e da verdadeira inserção solidária das singularidades sociais e interculturais nos processos de educação, ou em movimentos políticos.

A extensão universitária, como uma política educacional institucional, buscou oportunizar vivências educativas por meio da leitura literária, com os propósitos de uma escola criativa com formas de pensar e agir amplos, inter e transdisciplinares.

O encantamento pelo livro foi aguçado com a escolha dos temas desenvolvidos, pois contribuíram para compreender as relações conceituais que emergiram. A coletividade na leitura e escuta dos textos literários foram sensibilizadores e contagiantes. Após cada contação era promovido o diálogo, ampliando o conhecimento das relações estabelecidas nos textos e outras obras foram citadas e desejadas. 
O incentivo à leitura do literário e envolvimento desejante tornou-se evidente. Os circuitos de leitura possibilitaram a integração do grupo, o fortalecimento da expressão, do pensamento, da sensibilidade, do desenvolvimento da escrita e da fluência na comunicação.

A sensibilização, perante os temas e conceitos dos textos, ficou evidente, pois foram realizadas muitas práticas criativas com expressões em diferentes linguagens e sensibilização na expressão verbal e não verbal. As obras reconhecidas nos encontros foram provocadoras de significados e sentidos para a vida e convivência na expressão coletiva, nas dinâmicas que registraram valores e descobertas.

Perante as inúmeras expressões dos participantes ficou evidente o desejo de ler mais intensamente, do reconhecimento da necessidade de leitura e da necessidade de ouvir a fim de ampliar o conhecimento. Sentimos que as vivências de leitura tocaram níveis profundos de consciência, na sensibilidade e pensamento.

A aplicação da "Roda da Leitura Transdisciplinar", portanto, possibilitou o acesso aos textos literários, envolvidos na contação de histórias, ampliando o vocabulário. Ocorreu o auxiliou à capacidade de leitura oral e a desinibição para falar em público; também incentivou a escrita e reflexões, motivando a interação entre os participantes e a descoberta dos valores humanos. Foi possível afirmar que as vivências fortaleceram o humanescer, a criatividade e a expressividade por meio da leitura do texto literário.

\section{REFERÊNCIAS}

BATALLOSO, M. Dimensões da psicopedagogia hoje: uma visão transdisciplinar. Brasília: Liber Livro, 2011.

BAUMAN, Z. Vida de consumo. Buenos Aires: Fondo de Cultura Económica, 2008.

BERTICELL, I.; SCHIAVIN, D. P. Significados da Pragmática Linguística na Formação de Leitores. Educação \& Realidade, Porto Alegre, v. 38, n. 2, p. 571586, 2013. Disponível em: http://www.scielo.br/pdf/edreal/v38n2/v38n2a13. pdf. Acesso em : 07 dez. 2017.

CANDIDO, A. O direito à literatura. In: Vários escritos. Rio de Janeiro: Duas Cidades/Ouro sobre azul, 2004. 
CANTON, K. Fadas que não estão nos contos - Uma Confusão de Contos Clássicos. São Paulo: DCL, 2010.

COLASANTI, M. A moça tecelã. São Paulo: Global, 2009.

COUTO, M. A infinita fiandeira. 2016. Disponível em: https://www.revistapazes.com/a-infinita-fiandeira/. Acesso em: 29 jul. 2019.

DITTRICH, M. G. Arte, criatividade, espiritualidade e cura. Blumenau: Nova Letra, 2010.

DITTRICH, M. G.; BERNARDO, L.; BARRETA, C. Tecnologia de abordagem transdisciplinar para o cuidado às pessoas com câncer de mama. Saúde \& Transformação Social. Florianópolis, v.3, n.3, p.44-51, 2012.

DITTRICH, M. G. LEOPARDI, M. T. Hermenêutica fenomenológica: um método de compreensão das vivências com pessoas. Discursos fotográficos. Londrina, v.11, n.18, 2015.

DITTRICH, M.G.; URIARTE NETO, Mário. Humanescer na saúde: um olhar sobre a formação universitária. FARHAT, E.M.P.; DITTRICH, M.G. Educação e saúde: políticas públicas e vivências dialógicas. Itajaí: Editora da UNIVALI, 2016.

DOLLOR, F. Pata Ti e Pata Tá. São Paulo: Seed, 1999.

GILMAN, P. De pouco se faz muito: Um conto adaptado da tradição judaica. São Paulo: Caramelo Didático, 2004.

GRIMM, J.; GRIMM, W. Branca de Neve. Disponível em: https://www. grimmstories.com/pt/grimm_contos/branca_de_neve. Acesso em: 29 jul. 2019.

JUNQUEIRA, S. Poesia na varanda. Belo Horizonte: Autêntica, 2011. 
LACHENMEYER, N. Bicos quebrados. São Paulo: Global, 2004.

LEGEAY, Chloé. Para que serve o livro. São Paulo: Ed. Pulo do Gato, 2012.

LETRIA, J. J. O espírito do Natal. 2015. Disponível em: https://biblioler.blogs. sapo.pt/o-espirito-do-natal-jose-jorge-letria-152901. Acesso em: 29 jul. 2019.

LUCINDA, E. Um dedinho de amor. 2002. Disponível em: https://www.extraclasse.org.br/opiniao/colunistas/2002/05/um-dedinho-de-amor-i/. Acesso em: 29 jul. 2019.

MATURANA, H. Cognição, ciência e vida cotidiana. 2. ed., Belo Horizonte: Editora UFMG, 2014.

MERLEAU-PONTY, M. Fenomenologia da percepção. 2. ed., São Paulo: Martins Fontes, 1999.

MORAES, M. C. Transdisciplinaridade, criatividade e educação. Fundamentos ontológicos e epistemológicos. Campinas: Papirus, 2015.

MORIN, E. A cabeça bem-feita: repensar a reforma, reformar o pensamento. Tradução Eloá Jacobina. 8. ed. Rio de Janeiro: Bertrand Brasil, 2011.

MORIN, E. O método I: a natureza da natureza. Tradução de Maria Gabriela de Bragança. 2. ed. Mira-Sintra, Portugal: Publicações Europa América, 1977.

NEITZEL, A. de A. Druska. Itajaí: Ed. da Univali, 2018.

NEITZEL, A; BRIDON, J.; WEISS, C. S. Mediações em leitura: encontros na sala de aula. Rev. bras. Estud. pedagog. (online), Brasília, v. 97, n. 246, p. 305$322,2016$.

NEVES, A. Margarida. Belo Horizonte: Abacatte, 2010.

RIOS, R. A vassoura da bruxa. São Paulo: Moderna, 1993. 
ROCHA, R. A primavera da lagarta. São Paulo: Salamandra, 2011.

ROCHA, R. Romeu e Julieta. São Paulo: Salamandra, 2009.

SISTO, C. Eles que não se amavam. Rio de Janeiro: Nova Fronteira, 2005.

SHELDON, D.; GRINDLEY, S. Mais ou menos Natal. 2014. Disponível em: http://byblosfera.blogspot.com/2014/11/mais-ou-menos-natal-de-dyan-sheldon-e.html. Acesso em: 29 jul. 2019.

TORERO, J. R.; PIMENTA, M. A. Os 33 Porquinhos. São Paulo: Companhia das Letrinhas, 2016.

TORRE, S. D. L. MORAES, M. C; PUJOL, M. Transdisciplinaridade e ecoformação: um novo olhar sobre a educação. 1. ed., São Paulo: TRIOM, 2008.

ZAPPONE, M. H. Y. Estética da recepção. In: BONNICI, T.; ZOLIN, L. O. Teoria literária abordagens históricas e tendências contemporâneas. 3. ed. Maringá: Eduem, 2009. 